\title{
Immigration Policy and the Future of Latino Families
}

\author{
My experiences are going to go with me. \\ -LUIS ESCOBAR
}

As he looked to the future, Luis could not help but look back. He remembered when he first arrived to the United States at the age of nine: "You think you're gonna walk into the Magic Castle and Mickey [Mouse] is going to greet you and pat you in the back." Instead, he was dropped into the harsh reality of South Central Los Angeles, living with his mom and younger brother in a plastic garden shed behind his older brothers' house. They never went to Disneyland.

It was the early 1990s, and California raged with anti-immigrant sentiment. Luis remembered that Governor Pete Wilson and California voters wanted to "flag undocumented students from high school and deport them as soon as they turn 18." This was not exactly what Proposition 187 entailed, but he and his family were scared: "psychological suppression that you gotta be afraid, you gotta hide." Struggling to find a place to belong, he became involved in a community-based organization dedicated to empowering youth. He found a purpose advocating with his peers for better school resources.

Luis graduated from high school in 2001. Unlike most undocumented youth, he had mentors who knew about Assembly Bill 540, a recently passed state law that allowed him to pay in-state college tuition. He began community college. Drained by four hours on the bus each day, he invested in a car. It was almost older than he was, and he had to stop every 30 minutes to put water in the radiator. It took five years to transfer to a four-year university: "Sleep[ing] in the car in between classes, lots of coffee. Eating [only] bread and butter" to save enough money to pay tuition costs out of pocket. He temporarily left school when he was pulled over and cited for driving without a license so he could save up and pay the impound fees for his towed car. 
Despite these immense barriers, he eventually earned his bachelor's degree. As college graduation approached, Luis married his girlfriend with the dream of legalizing his status through marriage. He planned to "be an engineer. . . . [with] all this money." They soon learned that he would be unable to safely legalize his status because he had entered the United States without a valid visa. Older, and a little wiser, he got "a reality check. ... The older you get as a DREAMer, the harder it is to get a job because they don't look at you like, 'Aww, DREAMer, let me hook you up.' No, you are a grown undocumented person.” He continued to push forward, but the barriers were formidable for him, his wife, and their children.

Luis did what he could to disrupt the power that immigration policies held over his family. But, at the end of his first interview in spring 2012, he was resigned: "I've given my soul, my blood, my heart, my sweat to this country. I prayed, I've protested, I've hurt my back. My family is completely damaged. . . . So now I have a daughter, and I have to do whatever it takes to make a better life. . . If this country is gonna punish me even more, then I will have to take the punishment."

Two months later, DACA was announced.

We spoke again almost exactly two years after. Luis had received DACA and was using it to piece together a better future for his family. Picking at a plate of pancakes, he explained the mark his undocumented status had left on his life. He was one of the most upwardly mobile DACA recipients I spoke to, but he still felt vulnerable: "How do I live in that world [with DACA]? What are my new tools that I should have? Who am I now as a person compared to the person before? ... It was really like trying to let go of that person, but [I] couldn't let go of that person." Struggling with this transition, he concluded that, for better or worse, his life would always be shaped by his undocumented status.

Memories may fade, but his previous experiences shaped his deepest self.

Choices were made. Roads were not taken.

Time marched on.

Undocumented immigrants and their families are here to stay. They are woven into the social fabric of the United States, but as Luis's story exemplifies, they are simultaneously kept on the margins. Immigration laws and policies create a context of illegality that constrains opportunities and leaves undocumented young adults and their families swirling in uncertainty. These legal inequalities develop into social inequalities as hegemonic cultural ideals transform the material constraints associated with illegality into socioemotional barriers to participation. The very nature of families and family formation ensures that these inequalities endure, stretching into future generations.

The interplay between the law, cultural ideals, and families makes illegality consequential in everyday family life. Immigration laws and policies constrain 
family formation by limiting who undocumented young adults date, if and how they advance relationships, their relationship roles, and how they perform their roles as partners and parents. Their citizen romantic partners and children also contend with the material and emotional costs of punitive immigration policies. These constrained circumstances shape the life course of undocumented young adults and their citizen family members so that the imprint of undocumented status remains even as they transition into more inclusive immigration statuses. The longer we wait to address these legally imposed barriers, the more irreversible the consequences will become.

\section{CONSTRAINED CHOICES: IMMIGRATION POLICY, GENDERED EXPECTATIONS, AND ALTERED \\ FAMILY FORMATION}

Families are sites of social reproduction. Members of marginalized families share limited resources, allowing inequality to ripple through families and persist over generations. Such inequalities are increasingly produced through laws and legal institutions as the state disrupts family life, increasing the risk of long-term negative consequences. ${ }^{2}$ Immigration policies thus alter undocumented young adults' ability to build essential family relationships, constraining their choices and limiting their ability to meet their own and others' expectations.

Illegality limits the material resources available to build and sustain families. Undocumented young adults could not always afford to go out on dates, and they hesitated to risk driving without a license. They were denied access to agerestricted spaces and were infantilized as they tried to keep up with their citizen peers and partners. They struggled to deepen relationships because their intimate moments were rushed (and rare). These same barriers remained as they built families-permanently partnering, cohabitating, marrying, and having children. They worried about their capacity to support a growing family and doubted their ability to be the partner and parent that they wanted to be.

Illegality also frames relationships as a strategic means to an end. Popular narratives about legalization through marriage to a U.S. citizen took hold, shaping whom they were told to date (or not date), whom they allowed themselves to love, and when they chose to marry. If they were lucky enough to pursue legalization through marriage, laws shaped the very foundation of their life together as they structured their relationship to support their petition.

These limited resources and unstable beginnings endanger a relationship's capacity to provide emotional support and security. Relationships began with fears of inadequacy and (perceived) suspicion, requiring both partners to invest energy to prove their love. Differing immigration statuses, and the opportunities they dictate, infused inequality into relationships. Couples struggled with 
feelings of stress and guilt as they tried to build a brighter future, despite limited resources. Some successfully negotiated their different immigration statuses and built a sense of unconditional love and support. Others struggled for this mutual understanding. All together, these constraints led many undocumented young adults to internalize negative feelings about themselves as partners and parents.

These findings highlight how laws and hegemonic cultural ideals jointly make immigration status consequential in undocumented young adults' everyday lives. Immigration policies codify inequality along immigration status lines, creating unequal access to material resources. This restricts undocumented young adults' ability to participate in family formation in the ways that have become normalized by U.S. culture. In particular, gendered cultural ideals transformed material constraints into socioemotional barriers that disrupted family formation experiences and altered outcomes.

Steeped in traditional gender roles, undocumented young men aspired to be the provider. Early on, this manifested as expectations that they drive and pay for their dates. They dreamed of financial stability before transitioning to marriage and parenthood. This persistent desire to provide conflicted with their limited financial resources, and it endangered many men's ability to form families in the way they desired. Some prepared for a life of loneliness while others delayed taking on the added responsibilities of husband and father. Still many pushed on, committing themselves to partners and raising children despite their constrained circumstances. Although women also negotiated material and socioemotional barriers, their gendered expectations insulated them from severe consequences, ensuring that men's family formation was disproportionality disrupted in comparison. Thus, gender and immigration status mutually construct experiences of illegality. Future work should explore how other material constraints and cultural norms invoke social locations that intersect with undocumented status and that co-construct experiences of illegality.

In many instances, the stories of these undocumented young adults reflect those of low-income, incarcerated, or racial/ethnic minority citizens, in which structural barriers restrict family processes and produce negative family outcomes. ${ }^{3}$ I demonstrate how material constraints and socioemotional barriers come together in these marginalized families. Rather than become cultural innovators, undocumented young adults maintained hegemonic notions of family formation complete with gendered expectations, romantic images of love, and beliefs that there was a "right way" to form a family (whatever the specifics were). When illegality constrained their choices, it not only altered their ability to form families but also left them frustrated and dissatisfied that they could not live up to their own and others' expectations. This suggests that future research on marginalized families needs to deeply engage how material constraints and socioemotional barriers jointly (re)produce social inequalities via consequential family outcomes. 


\section{THE PASSAGE OF TIME: LIMITING THE BENEFITS OF INCLUSIVE IMMIGRATION POLICIES}

Immigration scholars have increasingly highlighted how laws and policies can restrict immigrant integration. For example, assimilation theory's use of context of reception highlights how governmental policy structures immigrant integration so that undocumented immigrants have lower incorporation levels. ${ }^{4}$ Further, substantive scholarship shows that moving from an undocumented to a lawful status improves economic and political integration. ${ }^{5}$ By focusing on the full process of family formation, I complicate the seemingly direct connection between lawful immigration status and immigrant incorporation. Rather, remnants of illegality endure, even as immigration policies change or individuals transition into more secure immigration statuses. I contend that the steady march of time pulls undocumented young adults along the life course, setting up consequences that outlast undocumented status.

Although not a formal legal status, receiving DACA reshaped the meaning of illegality overnight. DACA protections carried many material benefits associated with having a work permit, access to a valid Social Security number, and protection from deportation. Surveys show that DACA recipients moved into better jobs, had higher incomes, accessed financial accounts, bought cars and houses, stayed in or returned to school, and had better psychological wellness. ${ }^{6}$ Indeed, many of the DACA recipients I interviewed reported similar benefits. Everyone did not, however, benefit equally. Those with less education and weaker social networks were less likely to experience substantial mobility. ${ }^{7}$ While they may have moved into slightly better jobs, many did not have the requisite education, skills, or connections to launch themselves into the middle class. Those who had already formed families found it particularly difficult because they could not risk losing income and often lacked the time and resources to pursue new training or return for educational degrees. The same was true among the recently legalized lawful permanent residents.

Differential benefits aside, I find that the imprint of undocumented status remains because of family formation's time-dependent nature. Family formation is a key life course transition produced through a series of large- and smallscale choices that have long-term consequences because they affect subsequent life course transitions. ${ }^{8}$ Enduring consequences emerge because immigration policies constrain undocumented young adults' choices through this process. Relationships progressed as undocumented young adults awaited legal changes. They chose partners and made seemingly innocuous, but still significant, decisions about where to go on dates, if they should drive, or if they could enroll their children in an after-school activity. They made, or avoided making, life-altering commitments to partner, marry, or have children. All these choices remained with them, even when the sociolegal context improved. 
Receiving DACA helped many participants advance romantic relationships and fulfill parenting roles. Its impact was most positive when protections were acquired in time for key relationship transitions and when children were younger. Irreversible damage often remained, however: immigration policies had shaped whom they partnered with, left emotional scars, and produced internalized feelings of undesirability. For those who legalized through marriage, new consequences arose as couples constructed relationships that would facilitate the process. For many parents, legal changes came too late; they had missed their chance to provide their children with desired opportunities.

Enduring consequences likely emerge in other contexts, including education, employment, and political engagement. For example, undocumented high school and college students may give up on pursuing their education because they do not believe that they will use their degree to pursue a career and upward mobility. ${ }^{9}$ Obtaining DACA or another form of immigration relief does not change that these individuals will be ill positioned for upward mobility in an economic system that increasingly requires educational credentials. Similarly, in academic settings, immigration issues can distract undocumented students from their studies; news of a recent ICE raid may prevent them from studying or paying attention in class as they worry about their family's safety. These small moments can have farreaching, cumulative consequences-lowering their course grades and GPAs. ${ }^{10}$ In these ways, past experiences forever structure opportunities because they cannot be undone after a more secure legal status is obtained.

\section{MULTIGENERATIONAL PUNISHMENT: ENDURING CONSEQUENCES FOR FAMILIES AND COMMUNITIES}

In addition to enduring throughout an individual immigrant's life, illegality's consequences can stretch over generations. Citizenship does not protect family members from the legal violence perpetrated by immigration policies. Instead, multigenerational punishment emerges within mixed-status families as social ties and daily interactions lead citizens to witness and share in immigration policy's punitive effects. Citizen partners witness their undocumented partner's exclusion, help them negotiate barriers, and face negative material and emotional consequences. Citizen children's immediate everyday lives and future opportunities are similarly limited by their parents' immigration status. This ensures that illegality endures beyond the immigrant generation and perpetuates the marginalization of Latino families and communities.

Families' multigenerational nature ensures that immigration policies perpetrate multigenerational punishment. Shared consequences emerge because citizen family members have strong social relationships with undocumented immigrants. Children are inherently dependent on their parents, and romantic partners 
become interdependent as they commit to building a life together. Illegality thus constrains the intergenerational transmission of resources and limits the opportunities available to future generations.

The consequences of illegality are also shared more generally within the Latino community. Close cross-status relationships can occur in any kind of social relationship leading to shared consequences that likely depend on the depth of a person's relationship to undocumented immigrants. Like citizen partners and children, extended family and community members also helped undocumented young adults navigate immigration policies by registering their cars in their name, cosigning loans, or giving rides. Deportations tear apart not only families but also the social fabric of communities, as friends, coworkers, and neighbors mourn the deportation of their undocumented friends. ${ }^{11}$ Further, shared consequences can emerge absent direct social relationships to undocumented immigrants. Communities are socially and economically devastated when deportation removes community members and reduces remaining undocumented members' social and economic participation. ${ }^{12}$ The racialization of illegality as a Latino issue also ensures that documented immigrant and U.S.-born Latinas/os/xs face persistent exclusion because their race leads others to assume they are undocumented. ${ }^{13}$ This conflation can have significant population-level consequences: one study found that infants born to Latina mothers had a 24 percent greater risk of low birth weight after a large-scale immigration raid than those born during the same period a year earlier; notably, the risk increased for both citizens and immigrants. ${ }^{14}$

Ultimately, laws and policies that appear to target a single group actually restructure society so that the consequences of illegality extend beyond an isolated population segment. Illegality is woven deeply into Latino communities, given that almost half of the Mexican and Central American immigrant populations are undocumented. ${ }^{15}$ Mixed-status families abound as a quarter of Latino children have at least one undocumented parent. ${ }^{16}$ Mixed-status social relationships are also common; for example, a 2012 poll found that 63 percent of Latino registered voters nationally knew an undocumented immigrant. ${ }^{17}$ Thus, illegality has become a defining factor of Latino integration by embedding itself in the very foundation of families and communities.

The experiences of mixed-status Latino families provide a critical lens for explaining the broader incorporation patterns of Latino and Mexican-origin populations. Segmented assimilation theory has used Mexicans as a classic case of downward assimilation, highlighting worse incorporation outcomes over multiple generations when compared to other racial/ethnic groups. ${ }^{18}$ Comparisons within the Mexican-origin population show that there are improvements over generations, but that they do not necessarily achieve parity with whites. ${ }^{19}$ Scholars attribute these patterns to a variety of factors, including economic structures, weak coethnic community, and racialization. More recently, research has 
highlighted the high propensity of undocumented immigration status to figure as an additional reason for these lower incorporation outcomes. Frank Bean, Susan Brown, and James Bachmeier point to undocumented Mexican immigrants' "membership exclusion" as a key factor that hinders their incorporation and that of their children by fostering "formal and informal exclusion and stigmatization to the point of being deemed socially illegitimate." ${ }^{20}$ I highlight the intimate process behind this trend, illuminating how multigenerational punishment is an important mechanism driving the continued exclusion of Latino populations, particularly those of Mexican origin.

The enduring consequences of illegality likely have sweeping implications for other immigrant and racial/ethnic communities. About 24 percent of undocumented immigrants are not of Latin American origin; 12 percent come from Asia, 5 percent from Europe and Canada, 4 percent from the Caribbean, 2 percent from Africa, and 1 percent from the Middle East. ${ }^{21}$ Notably, Asian Americans and Pacific Islanders (AAPI) are the fastest-growing undocumented subgroup, more than tripling between 2000 and 2015, and accounting for about one in seven Asian immigrants. ${ }^{22}$ Despite racialized differences in experiences of illegality, ${ }^{23}$ AAPI and other non-Latino families and communities likely experience similar enduring consequences.

\section{CONSIDERING THE BROADER CONTEXT OF}

\section{ILLEGALITY: DIVERGING AND SHIFTING LAWS}

Immigration status is not an inherently significant category of difference, but it is made increasingly consequential by federal, state, and local government legislation. Such laws and policies produce immigrant illegality by limiting undocumented immigrants' everyday activities, decision-making, and upward mobility. Yet the stories of undocumented young adults and their mixed-status family members suggest that immigration policies extend their reach much deeper. I refer to the context of illegality to capture this dynamic and marginalizing social world constructed by immigration laws and policies. This broader focus imagines illegality as a sociolegal context to capture how it determines individual-level experiences, as well as familial and societal ones. Rather than attributing shared consequences to chance, it recognizes them as broader, systemic inequalities that have been created by immigration policies and become a source of intergenerational inequality for immigrants and Latino families and communities.

Illegality is context-specific because policies vary by place, change over time, and are implemented unequally. I focus on undocumented young adults in Southern California-a relatively protected population in one of the most supportive state and local contexts-as they transitioned into a more inclusionary form of liminal legality through DACA. Theirs is the quintessential best-case scenario. 
It seems likely that the consequences I have traced here are exacerbated in more exclusionary cases.

As new federal, state, and local level policies are implemented, illegality can become more or less consequential over time and in different places. Tracing DACA recipients' experiences allowed me to show how federal-level changes to immigration policy can create a less consequential form of undocumented status that alters how these select undocumented youth experience illegality. Importantly, subfederal policies, such as college tuition equity or financial aid provisions, can intervene to create state-level differences in the extent to which undocumented young adults can capitalize on DACA to redirect their life pathways. ${ }^{24}$ State and local policy changes can similarly make undocumented status less consequential. For example, in 2019, 13 states; Washington, DC; and Puerto Rico had laws making driver's licenses available to undocumented immigrants. ${ }^{25}$ Some cities, like New York and San Francisco, offer municipal identification cards. ${ }^{26}$ Several states, counties, and cities have established laws or policies that limit their cooperation with immigration enforcement officials. ${ }^{27}$ Further, immigrants' experience and negotiation of illegality are structured by place-based characteristics such as population demographics, the immigrant economy, the capacity of the local social service sector, geography, and the organization of housing, public space, and public transportation. ${ }^{28}$

Subfederal policies seek to soften illegality's everyday consequences. However, just as many state and local policies strive to make immigration status more limiting-increasing collaborations with immigration officials, barring access to education and other social services, preventing landlords from renting to undocumented immigrants, and criminalizing undocumented immigrants who are present and seek employment. ${ }^{29}$ Although these policies do not change one's immigration status, they leverage the balance of power between the federal and state/local governments to change the significance of undocumented status in everyday life. ${ }^{30}$

These policies can also shift over time. While California is currently one of the most inclusionary states, this has not always been the case. As Luis remembered, California has a dark, not-so-distant past of anti-immigrant legislation. The 1990 s saw voter-approved propositions that banned undocumented immigrants from accessing education, nonemergency health care, and other public services..$^{31}$ California became incrementally more progressive, with the context of illegality slowly bending toward inclusion..$^{22}$

An individual's experience of the context of illegality also varies based on their other social locations. When forming families, gender differentiates how undocumented young men and women experience illegality. Likewise, intersectional social locations-including race/ethnicity, class, immigrant generation, and sexual orientation-shape various outcomes, including educational and employment experiences, access to integrative resources and legalization 
opportunities, legal consciousness and activism, and deportation risks. ${ }^{33}$ Although the general character of illegality may seem the same, individual experiences vary greatly.

In many ways, the stories I have told here are those of a unique population forming families in a distinct place and time. Specific experiences may be different in other places; for example, deportation fears may be more prominent in places where immigration enforcement strongly collaborates with local police. Interviewing the same participants under Donald Trump's presidency would likely reveal increased uncertainty because of the legal precarity of the DACA program and the hypervisibility of immigration enforcement. All this variation, however, can be traced back to immigration laws and policies that configure the specific nature of illegality and structure the evolution of its enduring consequences. As a concept, context of illegality invites us to move beyond the specifics of a case to envision the dynamic production of illegality and its broader consequences for families and communities.

\section{FOSTERING INCLUSION AND RESILIENCE IN IMMIGRANT FAMILIES}

In addition to erecting structural barriers, illegality manifests in everyday family life as social stigma: judgment for one's partner choices, suspicion of marriage decisions, and condemnation for not meeting partner and parenting expectations. Few openly discussed these topics, not even with partners, friends, or family. The stigma was too strong for some, and others tried to ignore the issue, seemingly hoping that this might insulate them from its effects. But those who had open and honest conversations seemed the most successful at destigmatizing the limitations created by illegality and fostering healthy family dynamics. Partners who openly renegotiated gendered expectations could imagine and pursue a future together without infusing their everyday lives with risk and resentment. Parents sought to empower children with informed understandings of the law, knowledge about their opportunities as citizens, and a sense of justice.

If we want to keep the law from punishing families, we all have a responsibility to be vigilant of the small, day-to-day ways illegality can creep into relationships. We must remove the stigma of the marriage myths by pointing a finger where it belongs - at the laws that constrain choices. We must call out jokes about marrying a citizen and demands to do so, correcting misconceptions with legal realities. We must stop invalidating and judging relationships simply because they do not meet conventional expectations. We must support parents as they make difficult decisions about what avenue might best ensure their children's physical and emotional well-being. Open and honest conversations will be critical to destigmatizing the grip that the law holds on immigrant families. This may help curtail some of 
the socioemotional consequences until policymakers implement changes to dismantle illegality and the exclusionary context it creates.

\section{Policy Recommendations}

The United States has not seen comprehensive immigration reform since 1986. The experiences of young adults who legalized their status or obtained a liminal legal status through DACA show that integration depends on the creation of a pathway to legalization that will facilitate the integration of undocumented individuals, their families, and communities. Ultimately, legalization is the key to ensuring that immigrant families and communities can thrive and strengthen U.S. society. The long-standing absence of such pathways to legalization has ensured the enduring consequences of illegality.

It is critical that any future policies do not foster a sense of uncertainty. DACA was always conditional-its protections had to be renewed every two years, and there was always the possibility that a future presidential administration would discontinue the program. This reality led some recipients to avoid planning or preparing for the long term. Notably, recent plans outlining pathways to citizenship propose temporary or conditional statuses and long wait times for citizenship eligibility. While these policies may put people on the path to legal incorporation, shorter and clearer pathways are critical to limiting exclusionary consequences. Conditionality will keep applicants in limbo because they are unable to envision a certain future. This will likely curtail short- and long-term incorporation.

As policymakers debate whether and how to maintain U.S. immigration policy's grounding in family reunification, I offer a few words of caution. Any policy needs to provide for the reunification of immediate and extended family members to foster healthy families and communities. But making legalization opportunities contingent on family relationships-specifically on spouses and children-can be a double-edged sword. Specifically, current policies place too much pressure on families, disrupting family relationships and changing family formation processes. By requiring citizen partners and children to petition for their undocumented family members, we reproduce inequality within and among families. Further, current laws privilege citizen family members' pain over the struggles and contributions of undocumented individuals. This is not to say that we should eliminate family-based immigration policies, but rather that we need laws that value family ties, individual contributions, and the humanity of all involved.

Further, we need to recognize that legalization-whether it is for DACA recipients or all 10.7 million undocumented immigrants-is not a silver bullet. It will not undo the fact that a generation of immigrants has had every aspect of their lives shaped by immigration policies. We cannot ignore the damage that has been done. After a generation of finding ways to negotiate the laws and policies that exclude them, undocumented immigrants will need to learn to be legal. Further, as seen 
with DACA, integration is conditional on recipients' ability to translate their newfound legal integration into individual and family mobility. Social programs are needed to help undocumented immigrants acquire these missed skills and opportunities as they adapt to life after legalization. This could include campaigns and programming around educational access and employment skill building.

As we await comprehensive immigration reform, opportunities for integration exist in integrative state, local, and institutional policies. States, cities, and institutions can become sanctuaries, limiting their cooperation with immigration enforcement officials. IDs and driver's licenses issued by states, cities, and country-of-origin consulates can facilitate spatial mobility and social integration. Cities can decriminalize activities, like street vending, that lead to consequential police interactions and limit financial security. Schools and nonprofits can find novel ways of training undocumented immigrants to pursue entrepreneurship and self-employment in ways that limit their risk of financial instability and employer abuse.

Advocates should also examine seemingly unrelated policy areas for ways to facilitate integration. For example, providing all low-income children with access to social services, such as free or reduced-price lunch and Medicare, can minimize the impact of parental immigration status on children's academic outcomes. ${ }^{34}$ Broader social safety net programs for low-income families are, however, currently under attack. Congress's 2017-18 budget battle threatened funding for the Children's Health Insurance Program (CHIP), and President Trump proposed to slash the Supplemental Nutrition Assistance Program (SNAP). ${ }^{35}$ Programs like these are integral to immigrant families' well-being. To limit multigenerational punishment, policymakers must ensure that all children retain their rights to these programs and that immigrants are not punished for using social services. Indeed, proposed changes to "public charge" rules threaten to expand the forms of public assistance that would make an immigrant ineligible to receive permanent residency. ${ }^{36}$

\section{THE FUTURE OF IMMIGRANT FAMILIES: PERIL OR PROMISE?}

Aaron Ortiz gazed into the future as he watched his 18-month-old daughter chase birds around the Los Angeles arboretum. His dreams were no longer about his own success, but hers. He shared his hopes and fears for her future. He was adamant that she attend college. But he didn't know how he would afford all the opportunities he felt she would need to prepare for college-sports, tutoring, extracurricular activities. College tuition seemed even more out of reach. Recognizing that his undocumented status would limit his daughter, he was looking even further into the future. He would work hard so that his daughter "can get an 
easier lifestyle, and then her babies can be immune to this." Aaron saw another generation toiling for the mobility of those to come. He took solace in the thought that his daughter's citizenship status would shield her children in ways that he could not protect her.

Aaron hypothesizes just how enduring the punishment inflicted by immigration policies may be. Exclusionary immigration policies are already being felt by the next generation of Latino citizens. Will we pass inclusionary immigration policies to ensure that their children and grandchildren are immune? Will we treat them with love and give them papers? Or will we continue to wait, leaving families and communities in the wake of destructive and exclusionary policies?

As I wrote this book, debates and proposals for immigration reform raged. The early days of Trump's presidency were filled with fear that he would live up to his campaign promise to end the DACA program. A sigh of relief seemed to sweep over the nation as weeks passed and DACA remained intact. On September 5, 2017, however, the Trump administration announced its plan to phase out the program over the next two and a half years by allowing individuals' DACA protections to lapse. ${ }^{37}$

Public uproar ensued as states, universities, and DACA recipients filed court cases to challenge the decision..$^{38}$ A renewed movement to pass the federal DREAM Act emerged. Seven years after its last vote, Congress considered legislation providing a pathway to legalization for DACA recipients and other undocumented young adults. ${ }^{39}$ A decision by the 9 th District Court placed an injunction on DACA's rescission, noting that the "plaintiffs have clearly demonstrated that they are likely to suffer serious irreparable harm" if their protections lapsed. ${ }^{40}$

Meanwhile, the Trump administration sued California for its sanctuary policies, and U.S. Citizenship and Immigration Services changed its mission from ensuring "America's promise as a nation of immigrants" to "protecting Americans, securing the homeland." ${ }_{41}$ The world awoke to a humanitarian crisis at the U.S.-Mexico border: cries of terror-stricken detained migrant children separated from their parents filled the airwaves, and photos of teargassed Central American asylum seekers occupied the front page. ${ }^{42}$ Trump's call for a border wall streamed across social media and instigated a 35-day shutdown of the federal government. ${ }^{43}$

U.S. society is positioned to move in two distinct directions. We can develop and preserve laws and policies that, like DACA, will promote immigrant inclusion (even if imperfect). Or we can adopt increasingly draconian anti-immigrant measures that will exclude undocumented immigrants and their loved ones. The direction we move in will have sweeping implications now and far into the future. 